\title{
Epidermal Growth Factor Receptor Protein: A Biological Marker for Oral Precancer and Cancer
}

\author{
Ashish Mahendra, ${ }^{1}$ Balasundari Shreedhar, ${ }^{2}$ Mala Kamboj, ${ }^{2}$ Arun Singh, ${ }^{3}$ \\ Abhishek Singh, ${ }^{4}$ Ashutosh Agrawal, ${ }^{5}$ Sachin Kumar, ${ }^{3}$ and Arpita Kabiraj ${ }^{6}$ \\ ${ }^{1}$ Department of Oral Pathology \& Microbiology, Chandra Dental College Hospital, Safedabad, Barabanki 225001, India \\ ${ }^{2}$ Department of Oral Pathology \& Microbiology, Career Post Graduate Institute of Dental Sciences and Hospital, \\ Lucknow 226001, India \\ ${ }^{3}$ Department of Oral Pathology \& Microbiology, Kothiwal Dental College \& Research Centre, Moradabad 244001, India \\ ${ }^{4}$ Oral \& Maxillofacial Surgery, Kothiwal Dental College \& Research Centre, Moradabad 244001, India \\ ${ }^{5}$ Department of Oral Pathology \& Microbiology, Institute of Dental Sciences, Bareilly 243001, India \\ ${ }^{6}$ Department of Oral Pathology \& Microbiology, Haldia Institute of Dental Sciences and Research, Uttar Pradesh 721645, India
}

Correspondence should be addressed to Arun Singh; arunmci@yahoo.co.in

Received 15 October 2013; Revised 26 November 2013; Accepted 9 December 2013; Published 9 February 2014

Academic Editor: Kenji Yamagata

Copyright (C) 2014 Ashish Mahendra et al. This is an open access article distributed under the Creative Commons Attribution License, which permits unrestricted use, distribution, and reproduction in any medium, provided the original work is properly cited.

Background. The aim of the present paper was to study the expression and overexpression of EGFR in oral leukoplakia and cancer and at the same time assess the expression of EGFR in various histological grades of oral leukoplakia and OSCC in the Indian subcontinent. Methods. The study was conducted with routine H\&E and IHC staining on 40 archival tissues. Results. Positive EGFR staining was present in all the cases 100\% (30/30) out of which 7 (46.7\%) cases of OSCC showed $>75 \%$ EGFR expression and 8 (53.3\%) cases of oral leukoplakia showed 25\% EGFR expression. A statistically significant correlation was found in OSCC, OL and controls. Conclusions. EGFR may represent a promising target for novel molecular cancer therapies. EGFR expression levels in the premalignant lesion appear to be a sensitive factor in predicting the neoplastic potential of dysplastic tissues. This suggests that EGFR may serve as a biological marker to identify high-risk subgroups and guide prophylactic therapy.

\section{Introduction}

Oral cancer is the sixth most common cancer worldwide and has been marked by high morbidity and poor survival rates that have changed little over the past few decades. Beyond prevention, early detection is the most crucial determinant for successful treatment, better prognosis, and survival of cancer. Yet current methodologies for cancer diagnosis based upon pathological examination alone are insufficient for detecting early tumor progression and molecular transformation [1]. In India approximately $94 \%$ of oral malignancies are those of oral squamous cell carcinomas (OSCC) whose etiology is multifactorial with various intrinsic and extrinsic factors [2].

The proliferation and differentiation of cancer in the body are usually controlled by growth factors and their receptors on cancer cell surface. Epidermal growth factor receptor (EGFR), a tyrosine kinase receptor of the ErbB family, and the biological receptor of EGF and TGF- $\alpha$ are expressed or highly expressed in a variety of solid tumors, including oral cancers. Malignant oral keratinocytes possess from 5 to 50 times more EGFR than their normal counterparts [3]. It is found at abnormally high levels on the surface of many types of cancer cells, so these cells may divide excessively in the presence of epidermal growth factor. It is also termed as ErbB1 and HER1 [3].

In recent years, EGFR has been considered a promising target for monoclonal antibody therapy [4]. High EGFR expression has been correlated with tumor size, metastasis, and survival [5]. It is of great importance to conduct studies to determine the spectrum of mutations in the human EGFR 2 gene in order to gain a better insight into the mechanisms 
responsible for the overexpression of this frequently activated biomarker in human oral cancer. Oral tumors overexpressing EGFR exhibit a higher proportion of complete responses to chemotherapy than tumors with low-level EGFR expression [3]. Overexpression of EGFR presumably due to higher intrinsic proliferative activity could result in higher sensitivity to drug therapy cytotoxic to cells undergoing mitogenesis [5].

TGF- $\alpha$ is overexpressed early in oral carcinogenesis by hyperplastic epithelium and later by the inflammatory infiltrate, particularly the eosinophils, surrounding the invading oral epithelium. Concomitant expressions of TGF- $\alpha$ and EGFR may indicate more aggressive tumors than those overexpressing EGFR alone [6].

Current data suggest that a good number of epithelial cancers including oral squamous cell carcinomas (OSCC) overexpress EGFR and that monoclonal antibodies directed against EGFR may provide valuable information that would be useful in planning proper palliative treatment of certain premalignant and malignant lesions derived from squamous epithelium [7].

The aim of the present paper was to study the expression and overexpression of EGFR in oral leukoplakia and cancer and at the same time assess the expression of EGFR in various histological grades of oral leukoplakia and OSCC in the Indian subcontinent.

\section{Materials and Methods}

2.1. Selection of Subjects. The study was conducted on patients reporting to Career Post Graduate Institute of Dental Sciences and Hospital (CPGIDSH) and its associated hospitals, Lucknow, Uttar Pradesh, India, and a total of 40 biopsy proven cases (15 each of clinically proven leukoplakia and not from area adjacent to SCC (group II) and SCC (group I) and 10 age and sex matched controls cohort (group III)) were included in it. Control group tissue samples were collected from gingival tissues of premolars extracted for orthodontic purposes. Relevant data was recorded on a detailed pretested structured proforma schedule, by interviewing the prospective patients. The histological diagnosis of the cases was done based on the latest WHO consensus criteria.

2.2. Staining: Haematoxylin and Eosin. Formalin fixed, paraffin embedded sections of the normal, keratotic/dysplastic epithelium, and squamous cell carcinoma were stained by haematoxylin and eosin and the serial sections of the same were stained by immunohistochemical reagents. The samples were suspended in $10 \%$ buffer formalin for fixation variable period of time (about 24 hour) depending on the volume of the specimen. After tissues were adequately fixed, grossing of sample was done. Paraffin embedded formalin fixed tissues were processed and sectioned by routine method.

2.3. Immunohistochemical. Paraffin sections ( $5 \mu \mathrm{m}$ thick) were deparaffinized and rehydrated. Microwave antigen retrieval was done on sections in $0.01 \mathrm{~mol} / \mathrm{L}$ sodium citrate buffer ( $\mathrm{pH}$ 6.0), as per standard protocol, and endogenous peroxides were blocked using 3\% hydrogen peroxide for
30 minutes. Immunohistochemical staining for EGFR was done by streptavidin-biotin method with appropriate positive, negative, and reagent controls. The tissue sections were kept at $37^{\circ} \mathrm{C} \&$ fixed overnight at $60^{\circ} \mathrm{C}$ before immunohistochemistry. Dewaxing was done in xylene and rehydration was done in gradient alcohol (absolute alcohol of 70\%, 50\%) and finally in distilled water for $5 \mathrm{~min}$ each. Blocking was done by using $3 \% \mathrm{H}_{2} \mathrm{O}_{2}$ in methanol for $30 \mathrm{~min}$. Antigen retrieval was done using citrate buffer (ph 6.0) method to optimized staining for $120 \mathrm{~min}$ at $98^{\circ} \mathrm{C}$. The sections were immunostained with primary polyclonal antibody for EGFR (Biogenex, Bangalore, India). Sections were incubated overnight at $4^{\circ} \mathrm{C}$ with primary antibody in a humid chamber. The following day, sections were stained using labeled steptavidin Biotin biogenex kit (DAKO LSAB + system, K0679) with modified timings and sections were incubated for $2 \mathrm{hr}$ in the corresponding biotinylated secondary antibody solution followed by conjugated streptavidin horseradish peroxidase complex for $1 \mathrm{hr}$. Bound peroxidase was revealed using $0.05 \%$ 3 diaminobenzedine tetrahydro (DAB) in TBS. The sections were dehydrated, cleared, and mounted.

2.4. Evaluation of Study Results. EGFR immunostained sections were examined under light microscope. EGFR positive cells which showed staining for IHC were subjected to manual counting. Percentage of positive cells in individual case is counted in 5 high power fields in hot spot on the slide. Five positive fields in every case were photographed at low power (125x digital magnification) using Leica DFC camera mounted on a Zeiss Axiolab microscope. The digital images were analyzed in morphometry mode for percentage field area expressing brown color in Biovis image analysis software (Expert Vision Mumbai, India). Mean percentage area of EGFR positivity was taken. The statistical analysis was done using SPSS (Statistical Package for Social Sciences) Version 15.0 statistical Analysis Software. The values were represented in number (\%) and mean \pm SD.

\section{Results}

The objective of the present study was to evaluate EGFR expression as a marker for differentiation between oral cancer and precancerous lesions and to further make its quantitative assessment for use as a marker for differentiation in the different types/grades of cancer/precancerous lesions.

3.1. Oral Leukoplakia. Positive EGFR staining was present in all the cases $100 \%(30 / 30)$ out of which $8(53.3 \%)$ cases of oral leukoplakia showed 25\% EGFR expression (Figure 1).

3.2. OSCC. Positive EGFR staining was present in all the cases $100 \%(30 / 30)$ out of which $7(46.7 \%)$ cases of OSCC showed $>75 \%$ EGFR expression (Figure 2).

The EGFR expression was seen expressed with more intensity in cases of OSCC when compared to OL.

Tables 1(a) and 1(b) summarise the characteristics of EGFR expression in the various groups taken in the study and multiple comparisons made among the three study groups. 


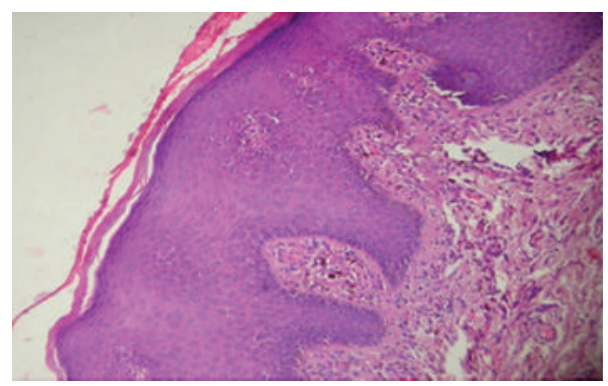

(a)

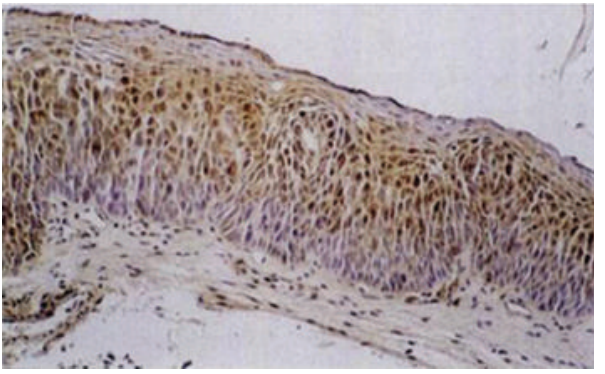

(c)

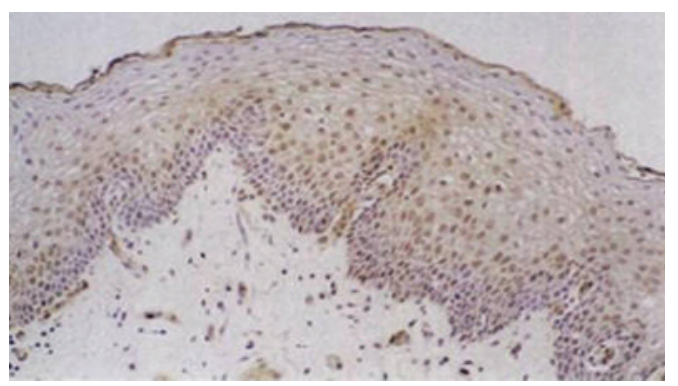

(b)

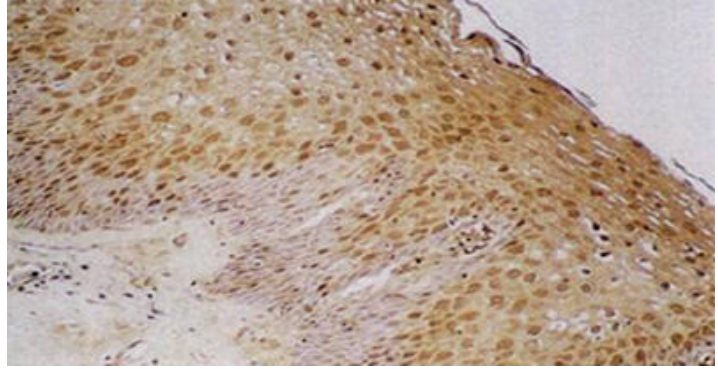

(d)

FIGURE 1: (a) A photomicrograph showing epithelial dysplasia (10x H\&E), (b) a photomicrograph showing mild dysplasia with detectable EGFR expression in the basal layer of keratotic epithelium (10x), (c) a photomicrograph showing moderate dysplasia with detectable EGFR expression in the basal, suprabasal, and lower spinous layers of keratotic epithelium (10x), and (d) a photomicrograph showing severe dysplasia with detectable EGFR expression in the basal, suprabasal, and lower spinous layers of keratotic epithelium (40x).

EGFR\% expression ranged from $15-95 \%$ in Group I (Mean $67.8 \pm 28.7$ ), $10-58 \%$ in Group II (Mean $24.6 \pm$ 14.0 ), and $0-10 \%$ in Group III (Mean $1.00 \pm 3.2$ ). A distinct distribution pattern was found among the groups. Carrying out multiple comparisons revealed a statistically significant difference between Group I and Group II $(P<0.001)$, Group I and Group III $(P<0.015)$, and Group II and Group III $(P<0.059)$.

Table 2 Depicts the Comparison of EGFR Expression with Individual Parameters of OL and OSCC Cases. In this paper, highly significant results were found when expression of EGFR was compared with age, tobacco habit, and duration of tobacco habit, due to which, probably, the OSCC cases showed higher EGFR expression when compared to OL cases. Statistically, no significant difference in \%EGFR expression in different $T$ stages was seen $(P=0.165)$. Owing to high within group variability (a long range), different $N$-stages had intervening and overlapping values, thereby showing no statistically significant difference in \%EGFR expression for different $N$-stages.

Tables 3(a) and 3(b) show the quantitative assessment of EGFR in histological types of OSCC and multiple comparisons between the three histological types of OSCC.

Statistically, no significant intergroup difference was seen $(P=0.612)$. Carrying out multiple comparisons revealed no statistically significant difference for any of the comparison $(P>0.05)$.

Tables 4(a) and 4(b) show quantitative assessment of EGFR in histological types Of oral leukoplakia and multiple comparisons between the three histological grades of dysplasia.

A limited utility of \%EGFR expression as a differentiation mean among different categories of leukoplakia was indicated. Statistically, a significant intergroup difference was seen $(P=0.008)$.

\section{Discussion}

The level of risk for malignant transformation of leukoplakia is associated with the lesion histology [5]. The ability to identify oral leukoplakia patients at increased risk of cancer development is critical for improving control of oral cancer. Once identified, the highest risk individuals could be offered more aggressive treatment options and more intensive followup. The leukoplakia is not only more than just a premalignant lesion but also a marker for increased cancer risk throughout the upper aerodigestive tract [5]. Recently, attempts were being made to identify specific molecular event(s) as prognostic markers to identify oral leukoplakia with higher malignant potential.

In our study, EGFR expression was observed in all the subjects of Group I and Group II and only 1 out of 10 had expression of EGFR in Group III. Statistically, there was a significant intergroup difference $(P<0.001)$. Group I and Group II had complete matching results, thereby showing no difference $(P=1)$; however, when compared to Group III, both had relatively higher expression of EGFR $(P<0.001)$; that is, expression in OL (epithelial dysplasia) was found 


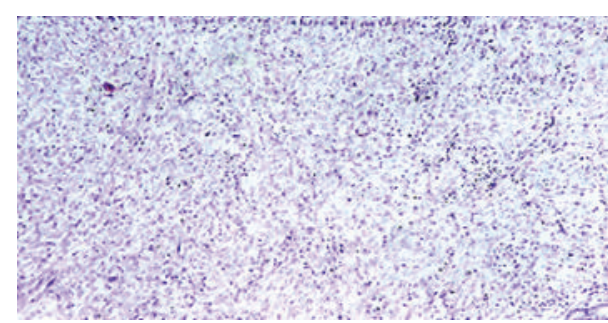

(a)

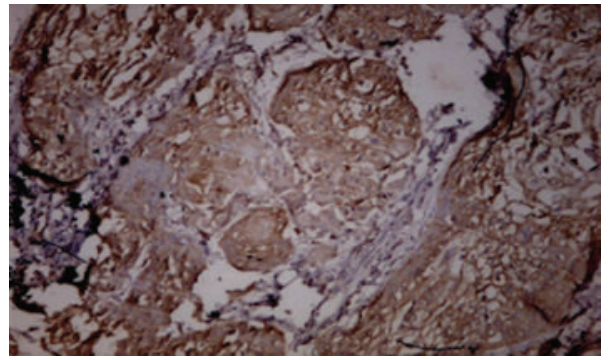

(c)

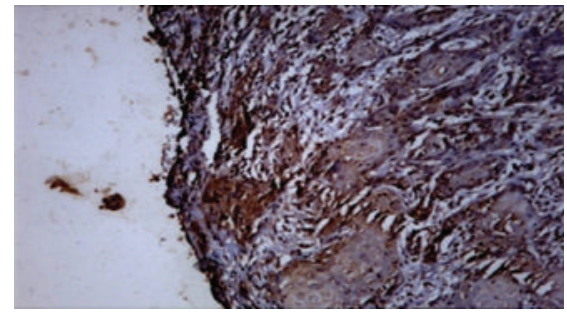

(b)

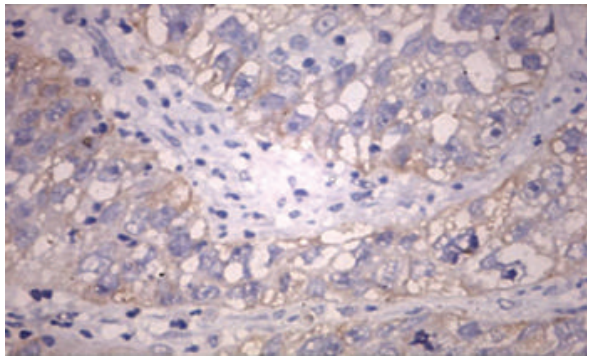

(d)

FIGURE 2: (a) A photomicrograph showing oral squamous cell carcinoma (10x H\&E), (b) a photomicrograph showing intense (93\%) EGFR expression in the peripheral cells of islands in well-differentiated squamous cell carcinoma (10x), (c) a photomicrograph showing intense (95\%) EGFR expression in the moderately differentiated OSCC (10x), and (d) a photomicrograph showing low (15\%) EGFR expression in the poorly differentiated OSCC (10x).

between 10 and $55 \%$ and more than 50\% expression in OSCC. A study in 2008 was conducted in which they found negative EGFR expression in normal oral mucosa, 25\% expression in epithelial dysplasia, and $40 \%$ expression in OSCC [8]. This proved significant difference in NOM (normal oral mucosa), ED (epithelial dysplasia), and OSCCs group $(P<0.05)$. In our study out of 15 OSCCs cases almost all of them showed positive expression. EGFR\% expression ranged from $15-95 \%$ in OSCCs (Mean 67.8 \pm 28.7 ). Similar positive EGFR expression results were $(92.3 \%)$ in OSCC cases, out of which in $63.2 \%$ it was very high [9].

In our study, a significant intergroup difference was seen $(P=0.008)$ in the various grades of dysplasia. In 1998 a study found EGFR elevated in epithelial dysplasia [10]. Carrying out multiple comparisons revealed a statistically significant difference between severe and mild dysplasia groups $(P=0.008)$ and no statistically significant difference between moderate, mild $(P=0.548)$, and severe dysplasia $(P=0.332)$ groups (Table $4(\mathrm{~b}))$. This shows that there is increased expression if it moved from mild to moderate and moderate to severe dysplasia. These findings supported the theory of field cancerization in head and neck tumorigenesis [11]. As tissue progressed from normal tissue adjacent to tumor to hyperplasia and to dysplasia, EGFR expression remained elevated. However, in the step from dysplasia to squamous cell carcinoma, EGFR expression was further and dramatically up regulated $(P=0.01)$ (Table $1(\mathrm{~b}))$. EGFR expression got increased from normal to dysplasia and then further increased from dysplasia to OSCCs in this study too.

The purpose of this study was to better understand the role of EGFR expression in head and neck tumorigenesis. It was seen that EGFR expression in the histologically normal-appearing epithelium adjacent to the tumors was twice as high as that in the normal control epithelial tissues in individuals. The second important observation of this study is that EGFR expression remained elevated through all of the premalignant stages of tumorigenesis and further increased in the change from dysplastic lesions to squamous cell carcinomas. This finding supports the concept of multistep tumorigenesis in the head and neck region. However, EGFR deregulation may control cell proliferation in this particular situation. That progression toward the malignant phenotype is accompanied by an accumulation of genetic damage in the exposed tissue that culminates in autocrine loop stimulation necessary for cell proliferation. It may take longer time period for the cells to transform from the genetically altered but histologically normal epithelium to the frank malignant phenotype. In the scheme of the multistep process of tumorigenesis, many genotypic and phenotypic alterations may be involved. Among these, a specific gene alteration may give a "hit" to the premalignant cells to transform toward the malignant phenotype. EGFR amplification and/or over expression may play this role in some cases; in other cases, the cells may be transformed at transcriptional regulation during the carcinogenesis process. A comparative study was done to see EGFR expression, and it was found that in OSCCs, EGFR is 69 times more than that in normal mucosa [12].

Similar results were seen in another study, in which a total of 52 patients with OSCC were selected for immunohistochemical analysis of EGFR and phosphorylated EGFR (p-EGFR) detection. Positive EGFR and p-EGFR staining was present in $92.3 \%(48 / 52)$ and $98.0 \%(51 / 52)$ of all cases, respectively. High EGFR and p-EGFR expression was present in $63.4 \%(33 / 52)$ and $69.2 \%(36 / 52)$ of all cases, respectively [9]. 
TABLE 1: (a) Characteristics of EGFR expression in oral squamous cell carcinoma, oral leukoplakia, and controls. (b) Multiple comparisons between the three study groups.

(a)

\begin{tabular}{|c|c|c|c|}
\hline Characteristics & Oral squamous cell carcinoma (Group I) & Oral leukoplakia (Group II) & Controls (Group III) \\
\hline \multicolumn{4}{|l|}{ Sex } \\
\hline Male & $11(73.3 \%)$ & $10(66.7 \%)$ & $6(60 \%)$ \\
\hline Female & $4(26.7 \%)$ & $5(33.3 \%)$ & $4(40 \%)$ \\
\hline \multicolumn{4}{|l|}{ Age } \\
\hline$\leq 40 \mathrm{yrs}$ & $2(13.3 \%)$ & $10(66.7 \%)$ & $4(40 \%)$ \\
\hline$>40 \mathrm{yrs}$ & $13(86.7 \%)$ & $5(33.3 \%)$ & $6(60 \%)$ \\
\hline \multicolumn{4}{|l|}{ Tobacco use } \\
\hline No & $0(0 \%)$ & $5(33.3 \%)$ & $8(80 \%)$ \\
\hline Yes & $15(100 \%)$ & $10(66.7 \%)$ & $2(20 \%)$ \\
\hline \multicolumn{4}{|c|}{$\begin{array}{l}\text { Duration of tobacco } \\
\text { use }\end{array}$} \\
\hline No history & $0(0 \%)$ & $5(33.3 \%)$ & $8(80 \%)$ \\
\hline Up to $10 \mathrm{yrs}$ & $4(26.7 \%)$ & $6(40 \%)$ & $2(20 \%)$ \\
\hline $11-20 \mathrm{yrs}$ & $8(53.3 \%)$ & $3(20 \%)$ & $0(0 \%)$ \\
\hline $21-30 \mathrm{yrs}$ & $3(20 \%)$ & $1(6.7 \%)$ & $0(0 \%)$ \\
\hline \multirow{3}{*}{$\begin{array}{l}\text { Histological } \\
\text { Diagnosis }\end{array}$} & WD $5(33.3 \%)$ & Mild $5(33.3 \%)$ & \\
\hline & MD $5(33.3 \%)$ & Moderate $5(33.3 \%)$ & \\
\hline & PD $5(33.3 \%)$ & Severe $5(33.3 \%)$ & \\
\hline \multicolumn{4}{|c|}{ EGFR expression } \\
\hline No & $0(0 \%)$ & $0(0 \%)$ & $9(90 \%)$ \\
\hline Yes & $15(100 \%)$ & $15(100 \%)$ & $1(10 \%)$ \\
\hline \multicolumn{4}{|l|}{$\begin{array}{l}\text { Extent of EGFR } \\
\text { expression }\end{array}$} \\
\hline $0-25 \%$ & $3(20 \%)$ & $8(53.3 \%)$ & $10(100 \%)$ \\
\hline $26-50 \%$ & $0(0 \%)$ & $6(40 \%)$ & $0(0 \%)$ \\
\hline $51-75 \%$ & $5(33.3 \%)$ & $1(6.7 \%)$ & $0(0 \%)$ \\
\hline$>75 \%$ & $7(46.7 \%)$ & $0(0 \%)$ & $0(0 \%)$ \\
\hline Mean \pm SD & $67.8 \pm 28.7$ & $24.6 \pm 14.0$ & $5.00 \pm 7.1$ \\
\hline Range & $15-95$ & $10-58$ & $0-10$ \\
\hline
\end{tabular}

(b)

\begin{tabular}{lccc}
\hline $\begin{array}{l}\text { Serial } \\
\text { number }\end{array}$ & Comparison & $Z$ & $P$ \\
\hline 1 & Group I (OSCC) versus Group II (oral leukoplakia) & 3.412 & $<\mathbf{0 . 0 0 1}$ \\
2 & Group I (OSCC) versus Group III (control) & 2.244 & 0.015 \\
3 & Group II (oral leukoplakia) versus Group III (control) & 1.976 & 0.059 \\
\hline Mann-Whitney $U$ test used.
\end{tabular}

EGFR and p-EGFR expression did not correlate with the clinical factors tumor stage, regional lymph node metastasis, or distant metastasis. However, a statistically significant correlation was identified between high EGFR expression and the pathologic factor tumor invasion. The majority of OSCCs highly express EGFR and p-EGFR, indicating the importance of studying the efficacy of anticancer therapy targeting these signal factors [9]. In this study, it was found that the majority of these tumors expressed EGFR and high expression of
EGFR did not correlate with clinical factors. Furthermore, a statistically significant correlation between high EGFR expression and the pathologic factor tumor invasion was identified [9].

EGFR expression levels in the premalignant lesions appear to be a sensitive factor in predicting the neoplastic potential of dysplastic tissues. This suggests that EGFR may serve as a biological marker to identify high-risk subgroups and guide prophylactic therapy. Such therapy could 
TABLE 2: Comparison of EGFR expression with individual parameters.

\begin{tabular}{|c|c|c|c|c|c|c|}
\hline Parameters & $n$ & Mean & SD & $Z / \chi^{2}$ & $P$ & Inference \\
\hline \multicolumn{7}{|l|}{ TNM staging $T$} \\
\hline$T 2$ & 5 & 74.8 & 33.9 & \multirow{2}{*}{$Z=1.416$} & \multirow{2}{*}{0.165} & \multirow{2}{*}{ NS } \\
\hline$T 4$ & 10 & 64.3 & 27.0 & & & \\
\hline \multicolumn{7}{|l|}{$N$} \\
\hline 0 & 4 & 57.3 & 35.6 & \multirow{4}{*}{$\chi^{2}=4.639$} & \multirow{4}{*}{0.200} & \multirow{4}{*}{ NS } \\
\hline 1 & 3 & 90.0 & 8.7 & & & \\
\hline 2 & 5 & 52.6 & 34.7 & & & \\
\hline 3 & 3 & 71.7 & 5.8 & & & \\
\hline \multicolumn{7}{|l|}{$M$} \\
\hline- & - & - & - & - & - & - \\
\hline \multicolumn{7}{|l|}{ Age } \\
\hline$\leq 40 \mathrm{yrs}$ & 12 & 27.9 & 21.7 & \multirow{2}{*}{$Z=2.135$} & \multirow{2}{*}{0.033} & \multirow{2}{*}{ Significant } \\
\hline$>40 \mathrm{yrs}$ & 18 & 55.8 & 33.6 & & & \\
\hline \multicolumn{7}{|l|}{ Tobacco habit } \\
\hline No & 5 & 11.5 & 6.2 & \multirow{2}{*}{$Z=3.316$} & \multirow{2}{*}{0.001} & \multirow{2}{*}{ Significant } \\
\hline Yes & 25 & 52.6 & 30.3 & & & \\
\hline \multicolumn{7}{|c|}{ Duration of tobacco habit } \\
\hline No history & 5 & 11.6 & 6.2 & \multirow{4}{*}{$\chi^{2}=12.645$} & \multirow{4}{*}{$<0.001$} & \multirow{4}{*}{ HS } \\
\hline Up to 10 & 10 & 50.9 & 27.3 & & & \\
\hline $11-20$ & 11 & 48.3 & 34.3 & & & \\
\hline $21-30$ & 4 & 68.8 & 27.5 & & & \\
\hline
\end{tabular}

TABLE 3: (a) Quantitative assessment of EGFR in histological types of OSCC. (b) Multiple comparisons between the three histological types of OSCC.

(a)

\begin{tabular}{|c|c|c|c|c|c|c|c|}
\hline \multirow{2}{*}{$\begin{array}{l}\text { Serial } \\
\text { number }\end{array}$} & \multirow{2}{*}{$\begin{array}{l}\text { Extent of EGFR } \\
\text { expression }\end{array}$} & \multicolumn{2}{|c|}{$\begin{array}{l}\text { Poorly differentiated } \\
\text { (PD) }(n=5)\end{array}$} & \multicolumn{2}{|c|}{$\begin{array}{l}\text { Moderately differentiated } \\
\quad(\mathrm{MD})(n=5)\end{array}$} & \multicolumn{2}{|c|}{$\begin{array}{l}\text { Well differentiated } \\
\text { (WD) }(n=5)\end{array}$} \\
\hline & & Number & $\%$ & Number & $\%$ & Number & $\%$ \\
\hline 1 & $0-25 \%$ & 2 & 40 & 1 & 20 & 0 & 0 \\
\hline 2 & $26-50 \%$ & 0 & 0 & 0 & 0 & 0 & 0 \\
\hline 3 & $51-75 \%$ & 1 & 20 & 2 & 40 & 2 & 40 \\
\hline 4 & $>75 \%$ & 2 & 40 & 2 & 40 & 3 & 60 \\
\hline \multicolumn{2}{|c|}{ Mean \pm SD } & \multicolumn{2}{|c|}{$53.2 \pm 35.3$} & \multicolumn{2}{|c|}{$69.0 \pm 32.9$} & \multicolumn{2}{|c|}{$81.2 \pm 7.4$} \\
\hline \multicolumn{2}{|r|}{ Range } & \multicolumn{2}{|c|}{$15-90$} & \multicolumn{2}{|c|}{$15-95$} & \multicolumn{2}{|c|}{$75-93$} \\
\hline
\end{tabular}

(b)

\begin{tabular}{lccc}
\hline Serial number & Comparison & $Z$ & $P$ \\
\hline 1 & PD versus MD & 0.841 & 0.421 \\
2 & PD versus WD & 0.943 & 0.421 \\
3 & MD versus WD & 0.318 & 0.841 \\
\hline \multicolumn{2}{l}{ Mann-Whitney $U$ test used. }
\end{tabular}

theoretically include monoclonal antibodies against EGFR, such as those used in patients with lung squamous cell carcinoma.

Expression of EGFR is a useful prognostic indicator which can be employed in the prediction of the survival of the patients with OSCC. One of the goals of this study was to identify regulatory markers that might be useful for assessing the risk of tumor development in histologically normal but carcinogen-exposed tissue and in leukoplakia. The results reported here were based on studies of leukoplakia in individuals with $100 \%$ risk of developing tumors (i.e., they had leukoplakia adjacent to squamous cell carcinomas). The studies presented here suggest that a determination of EGFR dysregulation might be not only a useful marker for 
TABLE 4: (a) Quantitative assessment of EGFR in histological types of oral leukoplakia. (b) Multiple comparisons between the three histological grades of dysplasia.

(a)

\begin{tabular}{lcccccc}
\hline \multirow{2}{*}{ Serial number } & \multirow{2}{*}{ Extent of EGFR expression } & \multicolumn{2}{c}{ Moderate $(n=5)$} & \multicolumn{2}{c}{ Severe $(n=5)$} & \multicolumn{2}{c}{ Mild $(n=5)$} \\
& & Number & $\%$ & Number & $\%$ & Number \\
\hline 1 & $0-25 \%$ & 3 & 60 & 0 & 0 & 5 \\
2 & $26-50 \%$ & 1 & 20 & 5 & 100 & 0 \\
3 & $51-75 \%$ & 1 & 20 & 0 & 0 & 0 \\
4 & $>75 \%$ & 0 & 0 & 0 & 0 & 0 \\
\hline \multicolumn{2}{c}{ Mean \pm SD } & $27.6 \pm 20.9$ & $32.0 \pm 4.5$ & 0 \\
\hline
\end{tabular}

(b)

\begin{tabular}{lccc}
\hline $\begin{array}{l}\text { Serial } \\
\text { number }\end{array}$ & Comparison & $Z$ & $P$ \\
\hline 1 & Moderate dysplasia versus severe dysplasia & 0.651 & 0.548 \\
2 & Moderate dysplasia versus mild dysplasia & 0.970 & 0.332 \\
3 & Severe dysplasia versus mild dysplasia & 2.703 & 0.008 \\
\hline
\end{tabular}

Mann-Whitney $U$ test used.

the identifying individuals at risk of tumor development but also a marker for an intermediate end point at which EGFR expression may be regulated by chemopreventive agents. Other biomarkers, associated with EGFR dysregulation during this complex pathway of tumorigenesis including proliferating cell nuclear antigen, p53 expression and mutations, and genetic alterations, are currently being explored to better understand the tumorigenesis of upper aerodigestive tract tumors. It is to be hoped that these biomarkers could be used as intermediate end points in chemoprevention trials in the near future.

\section{Conflict of Interests}

The authors declare no conflict of interests.

\section{Authors' Contribution}

Ashish Mahendra, Balasundari Shreedhar and Mala Kamboj were responsible for the design. Arun Singh collated the information. Abhishek Singh and Ashutosh Agrawal wrote the initial version of the paper, which was modified and edited by Sachin Kumar and Arpita Kabiraj.

\section{References}

[1] S. E. Weigum, P. N. Floriano, N. Christodoulides, and J. T. McDevitt, "Cell-based sensor for analysis of EGFR biomarker expression in oral cancer," Lab on a Chip, vol. 7, no. 8, pp. 9951003, 2007.

[2] A. T. Tandle, V. Sanghvi, and D. Saranath, "Determination of p53 genotypes in oral cancer patients from India," British Journal of Cancer, vol. 84, no. 6, pp. 739-742, 2001.

[3] D. T. W. Wong, R. Todd, T. Tsuji, and R. B. Donoff, "Molecular biology of human oral cancer," Critical Reviews in Oral Biology and Medicine, vol. 7, no. 4, pp. 319-328, 1996.
[4] W. G. Shafer, M. K. Hine, and B. M. Levy, "Benign and malignant tumors of oral cavity," in Shafer's Textbook of Oral Pathology, Elsevier, 5th edition, 2006.

[5] Y. Hiraishi, T. Wada, K. Nakatani, K. Negoro, and S. Fujita, "Immunohistochemical expression of EGFR and p-EGFR in oral squamous cell carcinomas," Pathology and Oncology Research, vol. 12, no. 2, pp. 87-91, 2006.

[6] J. Mendelsohn and J. Baselga, "Epidermal Growth Factor Receptor Targeting in Cancer," Seminars in Oncology, vol. 33, no. 4, pp. 369-385, 2006.

[7] M. A. S. Ali, M. Gunduz, H. Nagatsuka et al., "Expression and mutation analysis of epidermal growth factor receptor in head and neck squamous cell carcinoma," Cancer Science, vol. 99, no. 8, pp. 1589-1594, 2008.

[8] Y. Fong, S.-J. Chou, K.-F. Hung, H.-T. Wu, and S.-Y. Kao, "An investigation of the differential expression of Her2/neu gene expression in normal oral mucosa, epithelial dysplasia, and oral squamous cell carcinoma in Taiwan," Journal of the Chinese Medical Association, vol. 71, no. 3, pp. 123-127, 2008.

[9] Y. Hiraishi, T. Wada, K. Nakatani et al., "EGFR inhibitor enhances cisplatin sensitivity of oral squamous cell carcinoma cell lines," Pathology and Oncology Research, vol. 14, no. 1, pp. 39-43, 2008.

[10] J. Rubin Grandis, D. J. Tweardy, and M. F. Melhem, "Asynchronous modulation of transforming growth factor $\alpha$ and epidermal growth factor receptor protein expression in progression of premalignant lesions to head and neck squamous cell carcinoma," Clinical Cancer Research, vol. 4, no. 1, pp. 13-20, 1998.

[11] D. M. Shin, J. Y. Ro, W. K. Hong, and W. N. Hittelman, "Dysregulation of epidermal growth factor receptor expression in premalignant lesions during head and neck tumorigenesis," Cancer Research, vol. 54, no. 12, pp. 3153-3159, 1994.

[12] J. R. Grandis and D. J. Tweardy, "Elevated levels of transforming growth factor $\alpha$ and epidermal growth factor receptor messenger RNA are early markers of carcinogenesis in head and neck cancer," Cancer Research, vol. 53, no. 15, pp. 3579-3584, 1993. 


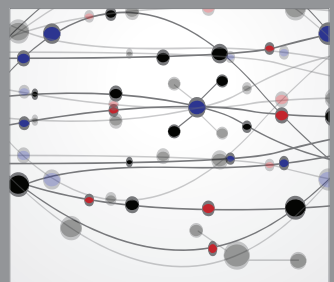

The Scientific World Journal
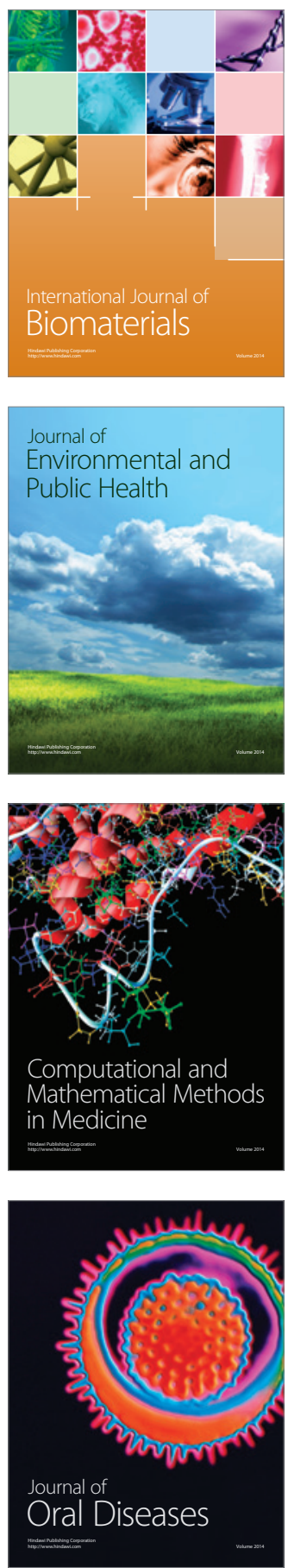
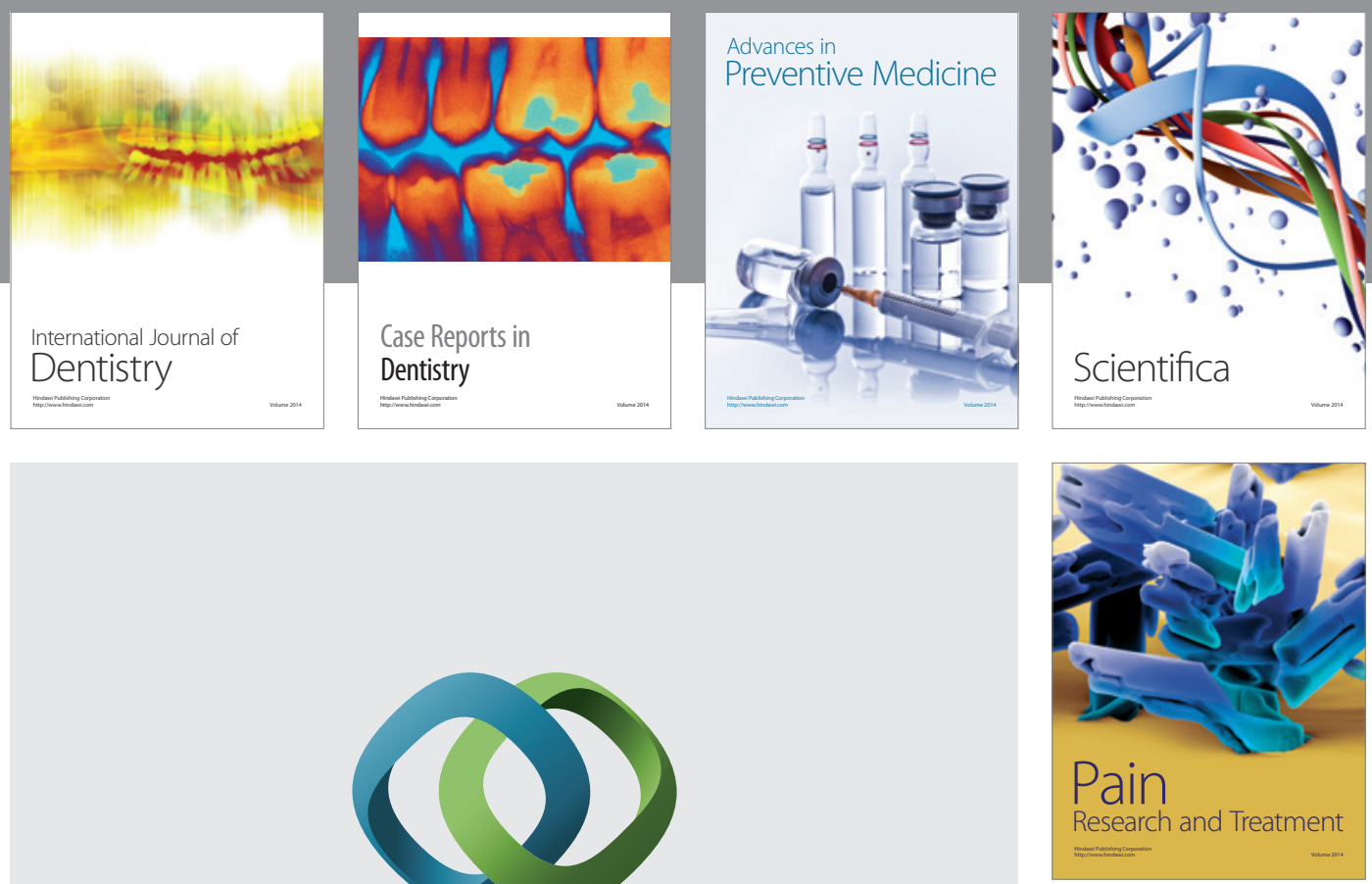

\section{Hindawi}

Submit your manuscripts at

http://www.hindawi.com
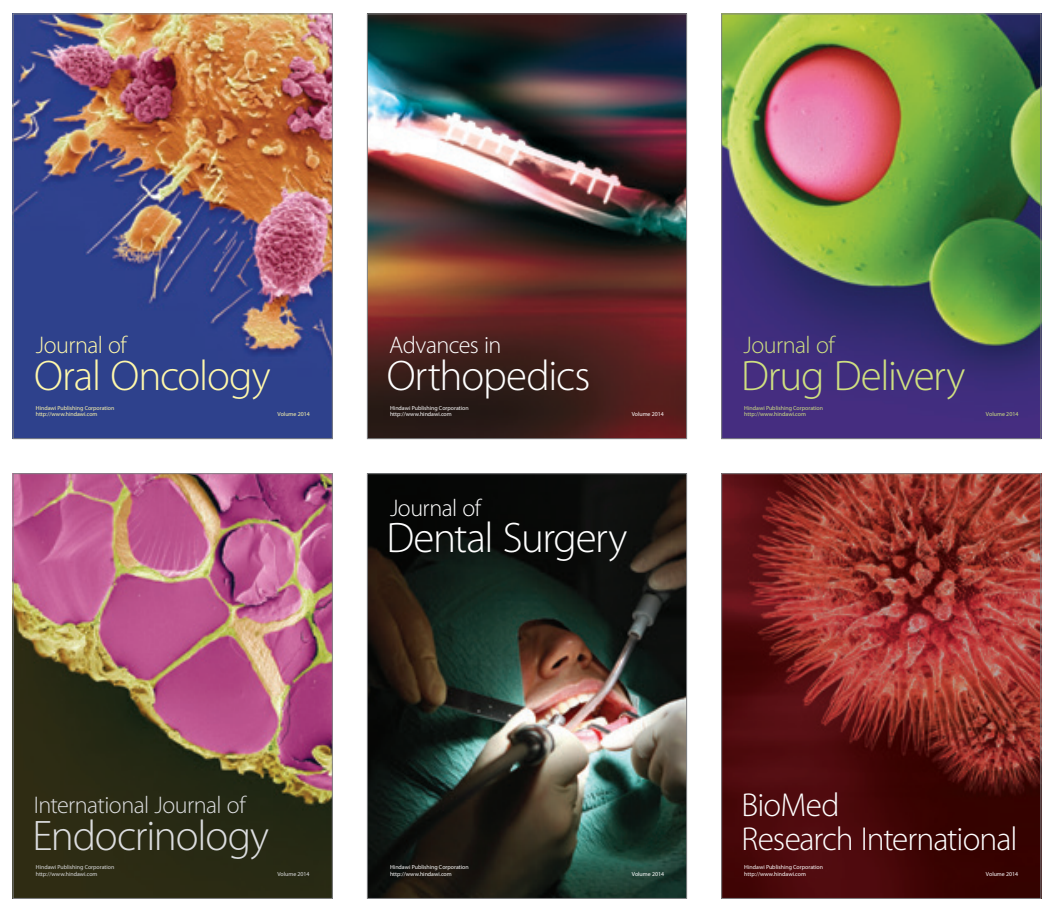

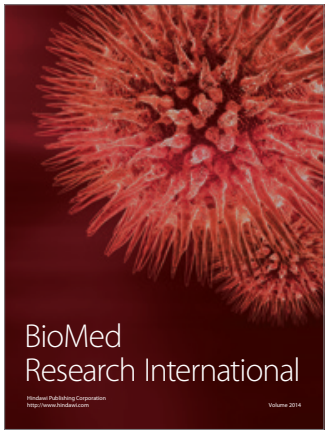

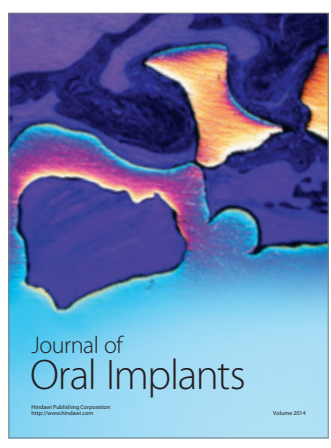
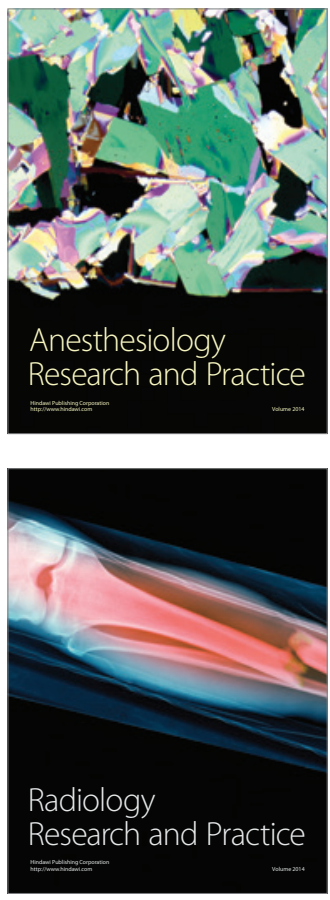